\title{
DOS CASOS DE UVEÍTIS SIFILÍTICA Y VIH
}

\section{TWO CASES OF SYPHILITIC UVEITIS AND HIV}

\author{
ZARALLO ${ }^{1}$, PASTOR B ${ }^{1}$, ASENCIO $\mathrm{M}^{1}$, SCHLINCKER A ${ }^{1}$, FONSECA A ${ }^{1}$
}

\section{RESUMEN}

Casos clínicos: Caso 1: paciente VIH+ que presenta una panuveítis unilateral. La exploración física muestra signos de sífilis secundaria. Se trata con excelente respuesta.

Caso 2: Paciente con panuveítis bilateral que ha recibido varios tratamientos durante meses en otro centro. En la anamnesis se detectaron factores de riesgo para SIDA, se realizan serologías que son positivas para VIH y sífilis y se procede al tratamiento.

Discusión: La sífilis está aumentando en los países desarrollados y sus manifestaciones en pacientes $\mathrm{VIH}+$ pueden ser atípicas. Una historia clínica adecuada es fundamental para un diagnóstico precoz. Los macrólidos pueden ser una alternativa en pacientes alérgicos a penicilina.

Palabras clave: Uveítis sifilítica, panuveítis, sífilis y VIH, neurosífilis, homosexual.

\begin{abstract}
Case reports: Case 1: HIV+ patient presenting unilateral panuveitis. Physical examination showed secondary signs of syphilis. The condition was treated with an excellent result.

Case 2: Patient with bilateral panuveitis having received different treatments in another centre for a period of months. In the anamnesis we detected risk factors for AIDS and ordered appropriate tests to be done, with the patient resulting positive for HIV and syphilis. We proceeded to treat.

Discussion: The incidence of syphilis is rising in developed countries and its manifestations in HIV+ patients can be atypical. An adequate clinical history is fundamental for an early diagnosis. Macrolides can be an alternative treatment in penicillinallergic patients (Arch Soc Esp Oftalmol 2008; 83: 197-200).
\end{abstract}

Key words: Syphilitic uveitis, panuveitis, syphilis and HIV, neurosyphilis, homosexual.

\footnotetext{
Recibido: 21/2/07. Aceptado: 12/2/08.

1 Licenciado en Medicina. (Madrid, 2006).

Servicio de Oftalmología. Hospital Universitario La Paz. Madrid. España.

Comunicación presentada en la 19 Reunión anual del Grupo Español Multicéntrico de Uveítis (Barcelona 2006) y en Seminario Castroviejo 


\section{CASOS CLÍNICOS}

\section{Caso 1}

Paciente de 38 años, bisexual, diagnosticado de infección por VIH en 1992, actualmente en estadio C3 $\left(\mathrm{CD}_{4} 291\right.$ células/ $\mu 1$, carga viral 4.400 copias/ml) acude al servicio de urgencias por ojo izquierdo (OI) rojo y con disminución de agudeza visual de tres días de evolución. El cuadro iba acompañado de un exantema que afectaba a palmas y plantas y malestar general de un mes de evolución

La exploración oftalmológica mostraba una agudeza visual de movimiento de manos en OI, con inyección conjuntival moderada, celularidad intensa y abundante fibrina en cámara anterior y sinequias posteriores (fig. 1). El fondo de ojo era inexplorable. Al día siguiente se pudo explorar el fondo tras una terapia intensiva con corticoides y midriáticos tópicos apreciándose intensa vitritis y condensaciones vítreas inferiores. En la exploración cutánea presentaba un exantema máculo-papuloso eritemato-violáceo, con lesiones en pequeñas placas ovaladas que afectaba también a palmas y plantas (fig. 2). Se realizaron serologías que resultaron positivas con RPR 1/32, IgG y TPHA positivas. Se practicó punción lumbar para el estudio del líquido cefalorraquídeo, obteniéndose un recuento celular de 2 leucocitos/ $\mu 1$ y algún hematíe, proteínas totales $295 \mathrm{mg} / \mathrm{dl}$, glucosa $65 \mathrm{mg} / \mathrm{dl}$ (glucemia simultánea $104 \mathrm{mg} / \mathrm{dl}$ ), VDRL e IgG sífilis negativos, anti-VIH positivos y aumento de la producción intratecal de inmunoglobulinas con $\operatorname{IgM} 2,1, \operatorname{IgG} 47$, IgG/albúmina 0,32.

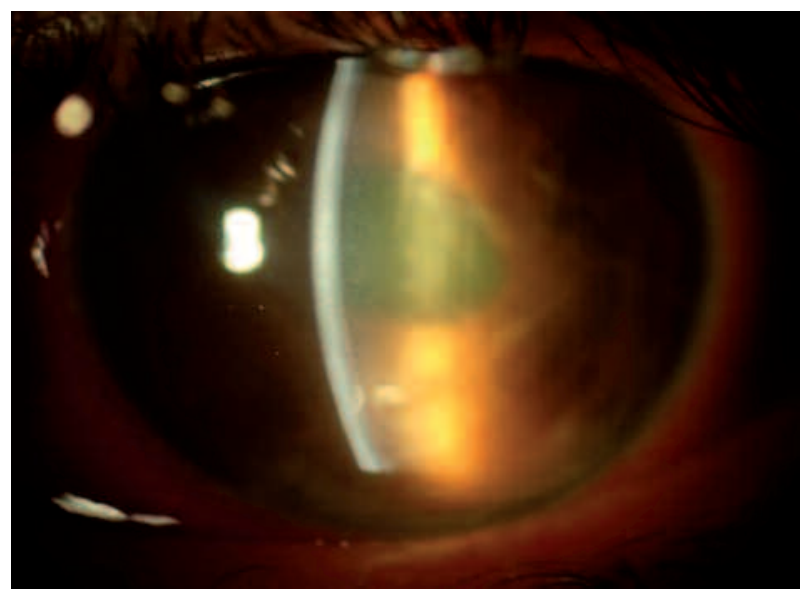

Fig. 1: Caso 1. Cámara anterior con fibrina, tyndall 4+ $y$ sinequias posteriores.

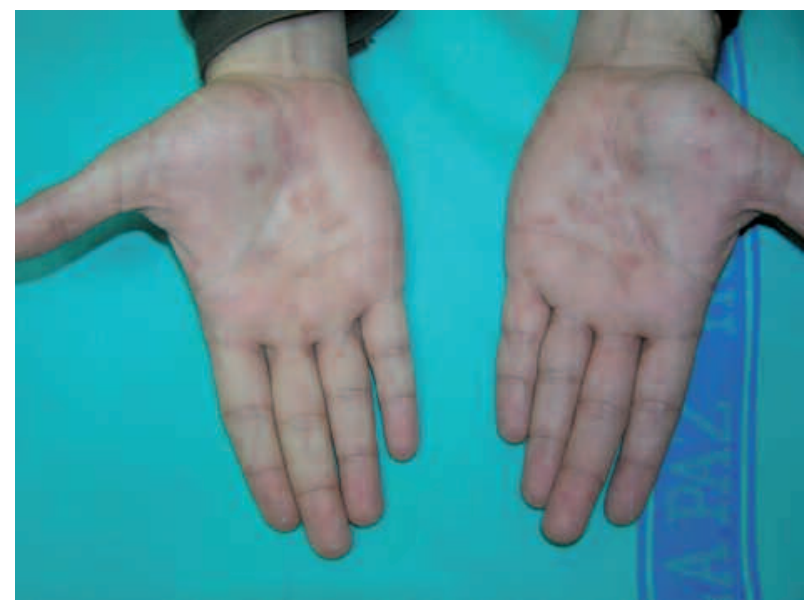

Fig. 2: Caso 1. Exantema máculo-papuloso con collarete de Biett.

Se inició el tratamiento tópico con corticoides y midriáticos, y sistémico con penicilina $\mathrm{G}$ sódica a dosis de 4 millones de unidades cada 4 horas durante 15 días. La evolución fue satisfactoria con recuperación de la agudeza visual hasta 0,9 , resolución de la inflamación y la vitritis y desaparición del exantema (fig. 3).

\section{Caso 2}

Paciente de 40 años remitido a nuestro centro tras un mes de tratamiento con corticoides intravenosos $\mathrm{y}$ orales y ciprofloxacino oral por un proceso que

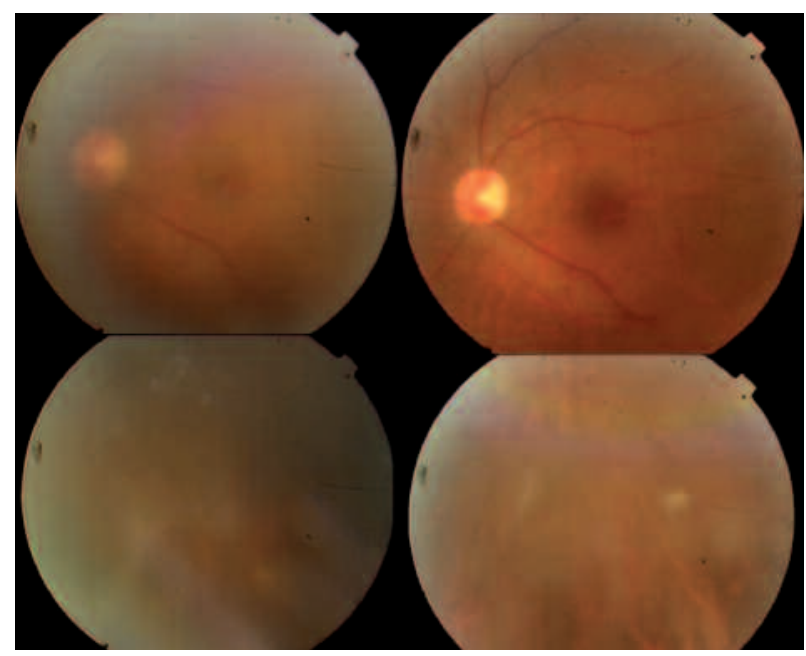

Fig. 3: Caso 1. Derecha: intensa vitritis el 2. ${ }^{\circ}$ día. Izquierda: clara mejoría una semana después. 
comenzó como papilitis bilateral y evolucionó a panuveítis bilateral. Nuestra historia clínica recoge que el paciente es homosexual con prácticas de riesgo, tiene una dudosa alergia a penicilina y tetraciclinas y cuatro meses antes del inicio de los síntomas oculares presentó un exantema palmo-plantar junto con clínica de faringitis aguda, tratada con eritromicina vía oral una semana.

En la exploración oftalmológica la agudeza visual era de 0,05 en el ojo derecho (OD, ojo ambliope) y cuenta dedos a $20 \mathrm{~cm}$ en el OI. Presentaba un defecto pupilar aferente relativo en OD. En la biomicroscopía se apreciaba celularidad moderada y precipitados retroqueráticos finos en $\mathrm{OD}$, en $\mathrm{OI}$ celularidad intensa, hipopión $1 \mathrm{~mm}$ y sinequias posteriores. En el examen funduscópico de ambos ojos se objetiva vitritis, papilitis y placas de coriorretinitis. En la exploración física se evidenciaba la existencia de adenopatías latero-cervicales bilaterales móviles no dolorosas.

El estudio analítico arrojó los siguientes valores: $\mathrm{CD}_{4} 522$ células/ $\mu 1$, carga viral 35.000 copias $/ \mathrm{ml}$, RPR positiva de 1/64 y TPHA e IgG (ELISA) positivos. Se diagnosticó como VIH+ en estadio A1 y posible secundarismo luético con afectación ocular por lo que se realizó punción lumbar con recuento celular de 5 células/ $\mu 1$, proteínas totales $234 \mathrm{mg} / \mathrm{dl}$, glucosa $80 \mathrm{mg} / \mathrm{dl}$ (glucemia simultánea 89) y VDRL negativo.

Con estos resultados se instauró tratamiento con bencilpenicilina intravenosa a dosis de 4 millones de unidades cada 4 horas iniciando a dosis bajas y en infusión lenta en el hospital de día de la Unidad de Alergia. El segundo día de administración el paciente desarrolló un cuadro de artralgias y exantema autolimitado interpretado como reacción de Jarisch-Herxheimer. Al noveno día reapareció un exantema sugestivo de toxicodermia que obligó a suspender el tratamiento. Se decidió continuar con eritromicina vía oral durante dos semanas dados los posibles antecedentes alérgicos del paciente.

La evolución fue favorable en 2-3 semanas, la agudeza visual es de 1/3 en OD y 1 en OI con resolución de las lesiones cutáneas y de inflamación ocular sólo restando unas placas hipopigmentadas en las zonas de las lesiones retinianas (fig. 4).

\section{DISCUSIÓN}

La correcta anamnesis y exploración del paciente es importante a la hora de pensar en la uveítis sifilí-

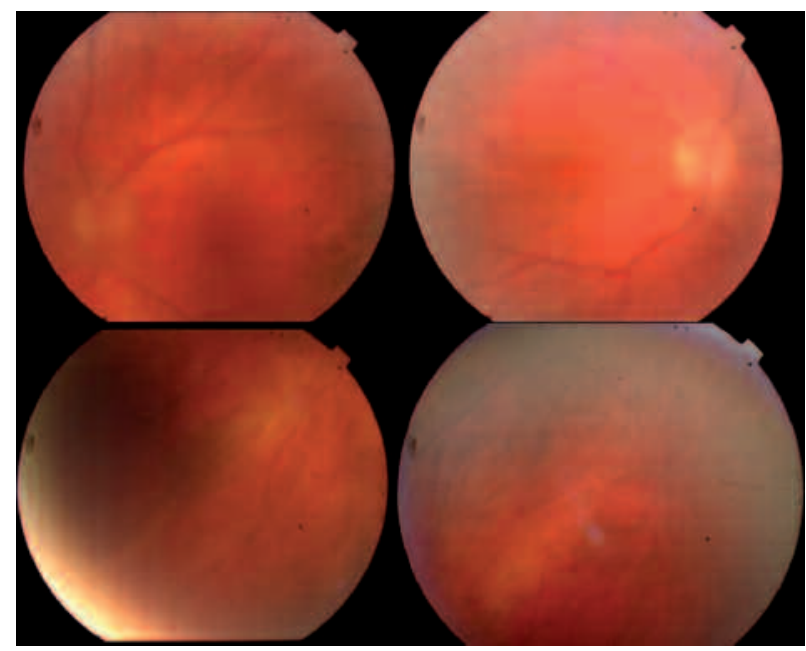

Fig. 4: Caso 2. Abajo: lesiones residuales amarillentas $y$ vitritis en resolución.

tica, especialmente en pacientes VIH. El tratamiento es el de la neurosífilis (1) con buenos resultados como en el primer caso. En casos de pacientes alérgicos se preconiza la desensibilización a la penicilina ya que no hay pautas claras sobre la duración y la dosis de otros tratamientos como los macrólidos (2). Nosotros utilizamos eritromicina con buen resultado. En ambos casos se practicó punción lumbar, imprescindible en la sífilis ocular (3).

Es un hecho objetivo el aumento de los casos de sífilis en los países desarrollados debido a la epidemia del SIDA (4). Además, las presentaciones atípicas de la uveítis sifilítica son frecuentes en los pacientes VIH+ y pueden ser la manifestación inicial de esta infección (5). Es necesario un alto índice de sospecha por parte del oftalmólogo y encuadrar la enfermedad ocular dentro del conjunto de hallazgos sistémicos, por lo que es necesaria la estrecha colaboración con el resto de facultativos que atiendan a estos pacientes.

\section{BIBLIOGRAFÍA}

1. Browning DJ. Posterior segment manifestations of active ocular syphilis, their response to a neurosyphilis regimen of penicillin therapy, and the influence of human immunodeficiency virus status on response. Ophthalmology 2000; 107: 2015-2023.

2. Aldave AJ, King JA, Cunningham ET Jr. Ocular syphilis. Curr Opin Ophthalmol 2001; 12: 433-441.

3. Gaudio PA. Update on ocular syphilis. Curr Opin Ophthalmol 2006; 17: 562-566. 
4. Doris JP, Saha K, Jones NP, Sukthankar A. Ocular syphilis: the new epidemic. Eye 2006; 20: 703-705.

5. Tran TH, Cassoux N, Bodaghi B, Fardeau C, Caumes E,
Lehoang P. Syphilitic uveitis in patients infected with human immunodeficiency virus. Graefes Arch Clin Exp Ophthalmol 2005; 243: 863-869. 